\title{
Osteoporosis and venous thromboembolism: a retrospective cohort study in the UK General Practice Research Database
}

\author{
G. Breart • C. Cooper • O. Meyer • C. Speirs • \\ N. Deltour $\cdot$ J. Y. Reginster
}

Received: 11 February 2009 /Accepted: 4 August 2009/Published online: 6 October 2009

(C) The Author(s) 2009. This article is published with open access at Springerlink.com

\begin{abstract}
Summary In a retrospective cohort study using the General Practice Research Database (GPRD), there was a greater association of venous thromboembolism (VTE) in osteoporotic than in non-osteoporotic female patients. No greater association was shown in treated patients with strontium ranelate or alendronate compared to untreated osteoporotic female patients.

Introduction We explored the risk of VTE in usual practice in osteoporotic and non-osteoporotic women with and without anti-osteoporotic treatment.

Methods A retrospective study was conducted using the GPRD in the UK. The cohorts consisted of untreated osteoporotic women $(N=11,546)$, osteoporotic women treated with alendronate $(N=20,084)$, or strontium ranelate $(N=2,408)$, and a sample of non-osteoporotic women $(N=$ $115,009)$. Cohorts were compared using a Cox proportional hazards regression model.
\end{abstract}

G. Breart $(\bowtie)$

INSERM U 953, Hôpital Tenon,

4 rue de la Chine,

75020 Paris, France

e-mail: gerard.breart@inserm.fr

C. Cooper

MRC Epidemiology Resource Centre,

University of Southampton,

Southampton, UK

C. Cooper

Institute of Musculoskeletal Sciences, University of Oxford,

Oxford, UK

O. Meyer

AP-HP Hôpital Bichat,

46 rue Henri Huchard,

75018 Paris, France
Results There was a significantly increased relative risk for VTE in untreated osteoporotic women versus nonosteoporotic women (annual incidence 5.6 and 3.2 per 1,000 patient-years, respectively; relative risk 1.75 [95\% confidence interval (CI), 1.09-1.84]). Results were confirmed using adjusted models. The annual incidences of VTE in osteoporotic patients treated with strontium ranelate and alendronate were 7.0 and 7.2 per 1,000 patient-years, respectively, with no significant difference between untreated and treated patients whatever the treatment. Adjusted hazard ratios for treated versus untreated osteoporotic women were 1.09 (95\% CI, 0.60-2.01) for strontium ranelate and $0.92(95 \% \mathrm{CI}, 0.63-1.33)$ for alendronate.

Conclusion This study shows a greater association of VTE in osteoporotic compared to non-osteoporotic patients, but does not show any greater association in treated patients with strontium ranelate or alendronate compared to untreated osteoporotic patients.

\section{Speirs}

John Kilner Diabetic Unit, Epsom Hospital,

Dorking Road, Epsom,

Surrey KT18 7EG, UK

N. Deltour

Institut de Recherches Internationales Servier, 92415 Courbevoie, France

\footnotetext{
J. Y. Reginster

Bone and Cartilage Metabolism Research Unit,

University of Liège,

Liège, Belgium
} 
Keywords Alendronate sodium · GPRD - Osteoporosis .

Risk factors $\cdot$ Strontium ranelate $\cdot$ Venous thromboembolism

\section{Introduction}

The incidence of venous thromboembolism (VTE) varies according to the presence of a number of risk factors; most notable are age, immobilisation, hospitalisation, and surgery $[1,2]$. In addition, ageing is accompanied by an increasing incidence of chronic diseases, which can impair general health status, and may also indirectly increase the risk for VTE [3]. One such chronic disease is osteoporosis, which leads to an increased risk for fracture, especially when it is associated with other risk factors, such as age, sex, history of fractures, low body mass index (BMI), or a recent fall [4-6]. The occurrence of osteoporotic fracture may in turn lead to immobilisation, hospitalisation, and surgery. By accumulating risk factors, ageing osteoporotic patients may, therefore, be particularly susceptible to VTE, though this has never been demonstrated.

The most commonly used agents to treat osteoporosis are bisphosphonates, calcitonin, raloxifene, parathyroid hormone, and strontium ranelate [7-10]. Analyses of the pooled populations of phase III studies for strontium ranelate have shown a slight increase in the annual incidence of VTE, with a relative risk of $1.4(95 \%$ confidence interval [CI], 1.0-2.0) versus placebo [11]. However, this increased risk with strontium ranelate remains weak when compared with treatments with a clear biological rationale for increasing VTE, such as selective oestrogen-receptor modulators or oestrogen replacement treatment [12-15].

The objectives of this study were to explore the incidence of VTE and its risk factors in osteoporotic and non-osteoporotic women and to investigate the relationship between the incidence of VTE and the anti-osteoporotic treatments strontium ranelate and alendronate sodium. Alendronate sodium is the most highly prescribed bisphosphonate in the UK and has never been associated with an increased risk for VTE.

\section{Methods}

\section{Data source}

The General Practice Research Database (GPRD) contains anonymous electronic medical records from primary care in the UK. It encompasses a representative sample of approximately $6 \%$ of the population from around 450 practices throughout the UK. The GPRD is currently operated and maintained by a division of the UK Medicines and Healthcare Products Regulatory Agency (MHRA). The database includes information on patient demographics, outpatient drug prescriptions, symptoms and medical diagnoses, referrals to specialists and hospitals, outpatient laboratory test results, and lifestyle factors (e.g., BMI, blood pressure, smoking, and alcohol consumption). Contributing general practitioners are required to meet specific recording standards to be considered "up-to-standard" (UTS). The accuracy and completeness of data held in the GPRD has been confirmed [16, 17], as well as its validity for the study of VTE [18]. As a result, the GPRD data is considered to be of sufficiently high quality for medical research. This project was approved by the Independent Scientific Advisory Committee for MHRA database research on 18 February 2008.

\section{Study design and population}

A retrospective cohort study was conducted on permanently registered female patients aged 50 years or older who had a general practice consultation for osteoporosis or who received at least one prescription for strontium ranelate or alendronate sodium, following the date of launch of strontium ranelate in the UK (December 2, 2004).

Only patients with 6 months of UTS follow-up before the index date were included. The study population included patients with a first ever record and patients with a history of primary osteoporosis and/or drug prescription. The following cohorts were analysed: one cohort per antiosteoporotic treatment consisting of new prescriptions only as proposed by Ray et al. [19]; one cohort of untreated osteoporotic patients according to anti-osteoporotic drug prescriptions; and a reference cohort of non-osteoporotic female patients, which consisted of a population-based random sample of $20 \%$ of the female aged 50 years or older since December 2, 2004 without an osteoporosis diagnosis or an anti-osteoporotic prescription.

The index date was the first recorded visit for osteoporosis or the first prescription of strontium ranelate or alendronate sodium following this date, whichever came first. For the non-osteoporotic cohort, the index date was a computer-generated randomly dated in the first year after study entry.

Osteoporosis was defined using a list of terms in the Medical Directory for Regulatory Activities and then by searching and validating the corresponding codes in Read/ OXMIS dictionaries used in the GPRD. For drug substances names from the World Health Organization Drug Dictionary were used to identify and validate the corresponding Multilex (UK) drug substance name, substance strength, and route of administration for product terms used in the GPRD. 
Exposure and outcome

The period defined as follow-up was from the index date to the latest GPRD data collection or the patient's transfer out of the practice or death, whichever came first. The period of treatment exposure (strontium ranelate or alendronate sodium) was defined from the date of first prescription to the date of last prescription plus the average prescription duration. A 30-day time period was added to the end date, as is usual when reporting adverse events. Moreover, current exposure period (current users) was defined as the period described above, and a non-exposure period (non-users) was defined as the follow-up time outside this period, i.e., before or after treatment exposure [20, 21]. The outcome of interest was the first episode of VTE during exposure or follow-up period. VTE events were defined using Read/OXMIS terms and included deep venous thrombosis, pulmonary embolism, or retinal vein thrombosis [22].

\section{Confounders}

The following known factors associated with the risk for VTE were considered as potential confounding variables: age, personal history of VTE, past hospitalisations in the 12 months before the index date, previous referral to other specialities in the 12 months before the index date, number of GP consultations, fractures (lower limb, pelvis, or sacrum), major surgery (including abdominal, pelvic, or spinal surgery), malignant tumour, inflammatory bowel disease, varicose veins, heart failure, cerebrovascular diseases, atrial fibrillation, smoking status, alcohol consumption, and BMI [2, 23-25]. Some prescriptions were also included as potential confounders: oestrogen replacement therapy for at least 3 months, number of previous osteoporotic treatments, and long-term use (more than 3 months) of oral corticosteroids [23, 26]. All covariates were assessed prior to the index date at any points in the available history after the UTS date, except for prescriptions, which were assessed in the 6 months prior to the index date, and fractures and surgery, which were also included whatever the time of occurrence.

\section{Comparison groups}

The incidence of VTE was compared between the untreated osteoporotic cohort and the non-osteoporotic cohort. The incidence of VTE in patients receiving strontium ranelate or alendronate sodium was then compared with the incidence in the untreated osteoporotic cohort.

\section{Statistical analysis}

The following analyses were conducted for each cohort: descriptive statistics on characteristics at index date, annual incidence of VTE expressed per 1,000 patient-years (PY) and time to first VTE using Kaplan-Meier life-table analysis. A Cox proportional hazards regression model was used to compare risk for VTE between cohorts. As a first step, we adjusted on age only since it is a well-known risk factor for VTE $[2,23,27,28]$. As a second step, risk factors and all confounders described above were tested in univariate analysis, and then included in backward selection to select the final fully adjusted regression models. For the comparison between the untreated osteoporotic and non-osteoporotic cohorts, we excluded the factors potentially linked to the osteoporosis itself (recent fractures and surgery during the study and referrals to other specialities as rheumatology, radiology, trauma, and orthopaedic clinic) in order to assess the proper impact of the osteoporosis disease on the risk for VTE and to avoid effects of over-matching. Sensitivity analyses were provided within each drug cohort to compare the incidence of VTE in current users versus non-users.

\section{Results}

The non-osteoporotic cohort comprised of 115,009 women. There was a total of 58,242 osteoporotic patients, of whom 11,546 were untreated. The follow-up periods were 241,261 PY for the non-osteoporotic cohort and 10,979 PY for the untreated osteoporotic cohort. Considering only new users, a total of 2,408 osteoporotic patients were treated with strontium ranelate and 20,084 with alendronate sodium. The prescription period was 1,859 PY for strontium ranelate (mean follow-up, 9.3 months) and 19,391 PY for alendronate sodium (mean follow-up, 11.6 months).

Table 1 summarises the baseline characteristics of the four cohorts. Patients in the osteoporotic cohorts were older than the non-osteoporotic cohort with a mean age of 74.1 years for osteoporotic patients treated with strontium ranelate or alendronate sodium and 70.8 years for untreated osteoporotic women versus 66.5 years for non-osteoporotic women. The mean BMI was higher in the non-osteoporotic cohort than in the untreated osteoporotic cohort. The number of patients with a medical history of VTE was higher in the untreated osteoporotic cohort (3.4\%) than in the non-osteoporotic cohort (1.6\%). For treated osteoporotic patients, the number of patients with a medical history of VTE was $4.2 \%$ in the strontium ranelate cohort and $3.8 \%$ in the alendronate sodium cohort. As would be expected, the osteoporotic cohorts included a higher number of patients with referrals to other services or specialities (such as rheumatology, radiology, traumatology, orthopaedic clinic, and X-ray), hospitalisations, fractures, and surgery. Similarly, fewer non-osteoporotic women had received oral corticosteroids within the 6 months before the index date. 
Table 1 Main characteristics of the cohorts at index date

\begin{tabular}{lllll}
\hline & Non-osteoporotic cohort & Untreated osteoporotic cohort & Treated osteoporotic cohort \\
\cline { 3 - 5 } & & & Strontium ranelate & Alendronate sodium \\
\hline Number of patients & 115,009 & 11,546 & 2,408 & 20,084 \\
Age (years) & $66.5 \pm 11.5$ & $70.8 \pm 10.8$ & $74.1 \pm 10.1$ & $74.1 \pm 10.3$ \\
Patients $\geq 80$ years & $18,776(16.3)$ & $2,700(23.4)$ & $802(33.3)$ & $6,775(33.7)$ \\
BMI, kg/m & $27.1 \pm 5.6$ & $25.2 \pm 5.0$ & $24.4 \pm 4.9$ & $25.4 \pm 5.2$ \\
History of VTE & $1,838(1.6)$ & $395(3.4)$ & $100(4.2)$ & $768(3.8)$ \\
Medical history & & & $1,375(57.1)$ & $10,906(54.3)$ \\
Referrals ${ }^{\mathrm{a}, \mathrm{b}}$ & $32,124(27.9)$ & $6,442(55.8)$ & $323(13.4)$ & $1,699(8.5)$ \\
Hospitalisations ${ }^{\mathrm{b}}$ & $2,607(2.3)$ & $676(5.9)$ & $470(19.5)$ & $2,785(13.9)$ \\
Fracture & $3,100(2.7)$ & $1,181(10.2)$ & $445(18.5)$ & $3,555(17.7)$ \\
Surgery & $12,697(11.0)$ & $1,853(16.0)$ & $302(12.5)$ & $3,767(18.8)$ \\
Malignant cancer & $15,371(13.4)$ & $2,147(18.6)$ & & $2,215(11.0)$ \\
Varicose veins & $8,247(7.2)$ & $1,238(10.7)$ & & $74(3.1)$ \\
Previous treatments & & & $406(16.9)$
\end{tabular}

Data are number $(\%)$ or mean \pm standard deviation

$V T E$ venous thromboembolism (including deep venous thrombosis, pulmonary embolism, or retinal vein thrombosis), $B M I$ body mass index

${ }^{a}$ Referrals to other specialities (traumatology, radiology, and orthopaedic clinic)

${ }^{\mathrm{b}}$ Medical events within 12 months prior to the index date

${ }^{\mathrm{c}}$ Prescriptions $\geq 3$ months, up to 6 months before the index date

All these characteristics have been included in fully adjusted analyses for cohort's comparisons.

The annual incidence of VTE was 3.2 per 1,000 PY in non-osteoporotic women versus 5.6 per 1,000 PY in untreated osteoporotic patients. Table 2 shows the incidence of VTE in non-osteoporotic patients and osteoporotic untreated patients. Significant increased risk for VTE was observed (relative risk: 1.75 [95\% CI, 1.09-1.84]) in untreated osteoporotic cohort versus the non-osteoporotic cohort, which remained significant when adjusted for age (hazard ratio (HR), 1.43 [95\% CI, 1.10-1.86]). In fully adjusted model, the difference was still significant (HR, 1.38 [95\% CI, 1.03-1.86]). Figure 1 shows the cumulative incidence curve of first VTE during the follow-up period using Kaplan-Meier's method.

The annual incidence of VTE increased with age in both non-osteoporotic women and untreated osteoporotic patients: 2.4 and 4.3 per 1,000 PY, respectively, in women aged between 50 and 75 years; 5.2 and 7.2 per $1,000 \mathrm{PY}$ in women aged between 75 and 80 ; and 6.1 and 8.3 per $1,000 \mathrm{PY}$ in women older than 80 years.

Comparison of the incidence of VTE in untreated osteoporotic patients with the two cohorts of treated patients showed no significant difference (Table 3), in both the age-adjusted and in the fully adjusted models, and whatever the treatment may be. In the strontium ranelate-
Table 2 Incidence of VTE in non-osteoporotic women versus untreated osteoporotic patients

\begin{tabular}{lcc}
\hline & $\begin{array}{c}\text { Non-osteoporotic } \\
\text { cohort } \\
(N=115,009)\end{array}$ & $\begin{array}{c}\text { Untreated osteoporotic } \\
\text { patients } \\
(N=11,546)\end{array}$ \\
\hline Patients with VTE $(N)$ & 767 & 61 \\
Annual incidence & 3.2 & 5.6 \\
$\quad$ per 1,000 PY) & $1.75(1.09-1.84)$ \\
Relative risk (95\% CI) & $1.43(0.13)$ \\
Adjusted model on age ${ }^{\mathrm{a}}$ & $1.10-1.86$ \\
HR (SE) & 0.007 \\
$95 \%$ CI & \\
$p$ value & $1.38(0.15)$ \\
Fully adjusted model & $1.03-1.86$ \\
HR (SE) & 0.030 \\
$95 \%$ CI & \multicolumn{2}{c}{$\begin{array}{c}\mathrm{b} \\
p \text { value }\end{array}$} \\
\hline
\end{tabular}

VTE venous thromboembolism (including deep venous thrombosis, pulmonary embolism, or retinal vein thrombosis), $C I$ confidence interval, $H R$ hazard ratio, $S E$ standard error; $P Y$ patients-years

${ }^{\mathrm{a}} \mathrm{HR}$ between groups based on a Cox proportional hazards regression model adjusted on age

${ }^{\mathrm{b}} \mathrm{HR}$ between groups based on a Cox proportional hazards regression model fully adjusted for all confounders described in the Methods section (final regression model by backward selection) 


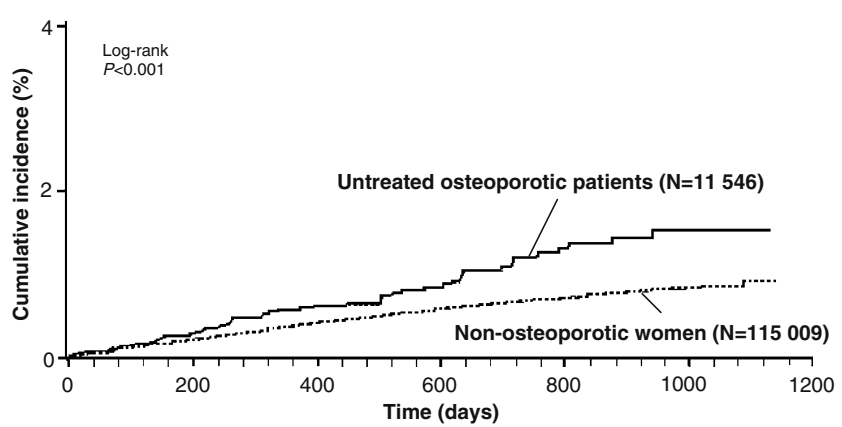

Fig. 1 Cumulative incidence curve of first venous thromboembolism in non-osteoporotic women and untreated osteoporotic patients (Kaplan Meier's method)

treated cohort, the incidence of VTE was 7.0 per 1,000 PY, with HRs of 1.15 (95\% CI, 0.63-2.1) and 1.09 (95\% CI, $0.60-2.01)$ in age-adjusted and fully adjusted models, respectively, versus untreated osteoporotic women. In the alendronate sodium-treated cohort, the incidence of VTE was 7.2 per 1,000 PY and the HRs were $1.10(95 \% \mathrm{CI}$, $0.81-1.50]$ and 0.92 (95\% CI, 0.63-1.33) in age-adjusted and fully adjusted models, respectively, versus untreated osteoporotic women.

The rate of mortality was similar for both cohorts, which are $2.9 \%$ in the strontium ranelate group and $4.0 \%$ in the alendronate group.

Table 3 Incidence of VTE in osteoporotic patients treated with strontium ranelate or alendronate sodium versus untreated osteoporotic patients

\begin{tabular}{|c|c|c|c|}
\hline & \multicolumn{2}{|c|}{ Treated osteoporotic patients } & \multirow{2}{*}{$\begin{array}{c}\text { Untreated } \\
\text { osteoporotic } \\
\text { patients } \\
(N=11,546)\end{array}$} \\
\hline & $\begin{array}{l}\text { Strontium } \\
\text { ranelate } \\
(N=2,408)\end{array}$ & $\begin{array}{l}\text { Alendronate } \\
\text { sodium } \\
(N=20,084)\end{array}$ & \\
\hline $\begin{array}{l}\text { Patients with } \\
\text { VTE }(N)\end{array}$ & 13 & 140 & 61 \\
\hline $\begin{array}{l}\text { Annual incidence } \\
\text { (per 1,000 PY) }\end{array}$ & 7.0 & 7.2 & 5.6 \\
\hline \multicolumn{4}{|c|}{ Adjusted model on age ${ }^{\mathrm{a}}$} \\
\hline HR (SE) & $1.15(0.31)$ & $1.10(0.16)$ & \\
\hline $95 \% \mathrm{CI}$ & $0.63-2.10$ & $0.81-1.50$ & \\
\hline$p$ value & 0.656 & 0.530 & \\
\hline \multicolumn{4}{|l|}{ Fully adjusted ${ }^{\mathrm{b}}$} \\
\hline HR (SE) & $1.09(0.31)$ & $0.92(0.19)$ & \\
\hline $95 \% \mathrm{CI}$ & $0.60-2.01)$ & $0.63-1.33)$ & \\
\hline$p$ value & 0.773 & 0.646 & \\
\hline
\end{tabular}

$V T E$ venous thromboembolism (including deep venous thrombosis, pulmonary embolism, or retinal vein thrombosis, $C I$ confidence interval, $H R$ hazard ratio, $S E$ standard error, $P Y$ patients-years

${ }^{a} \mathrm{HR}$ between groups based on a Cox proportional hazards regression model adjusted on age

${ }^{b}$ HR between groups based on a Cox proportional hazards regression model fully adjusted for all confounders described in the Methods section (final regression model by backward selection)
Table 4 Incidence of VTE in current users versus non-users of strontium ranelate or alendronate sodium

\begin{tabular}{lccccc}
\hline & \multicolumn{3}{c}{ Treated osteoporotic patients } \\
\cline { 2 - 3 } & $\begin{array}{c}\text { Strontium ranelate } \\
(N=2,408)\end{array}$ & & $\begin{array}{c}\text { Alendronate sodium } \\
(N=20,084)\end{array}$ \\
\cline { 2 - 3 } \cline { 5 - 6 } & $\begin{array}{c}\text { Non- } \\
\text { users }\end{array}$ & $\begin{array}{c}\text { Current } \\
\text { users }\end{array}$ & & $\begin{array}{c}\text { Non- } \\
\text { users }\end{array}$ & $\begin{array}{c}\text { Current } \\
\text { users }\end{array}$ \\
\hline Patients with VTE $(N)$ & 34 & 13 & & 230 & 140 \\
Annual incidence & 6.8 & 7.0 & & 6.2 & 7.2 \\
(per 1,000 PY) & $0.90(0.34)$ & & $0.99(0.11)$ \\
HR (SE) & & $0.46-1.75$ & & $0.80-1.23$ \\
95\% CI & \multicolumn{2}{c}{0.75} & & 0.96 \\
$p$ value & & &
\end{tabular}

During treatment exposure, patients belong to the cohort of current users; outside this period, they are considered as non-users

VTE venous thromboembolism (including deep venous thrombosis, pulmonary embolism, or retinal vein thrombosis), $C I$ confidence interval, $H R$ hazard ratio, $S E$ standard error, $P Y$ patients-years

${ }^{\mathrm{a}} \mathrm{HR}$ between groups based on a Cox proportional hazards model adjusted on age and with group included in a time-dependent fashion

Sensitivity analyses were performed within each cohort of treated osteoporotic patients (Table 4). The incidence of VTE during drug exposure (current users) was compared with the incidence when not exposed either before the beginning of the treatment or after treatment cessation (nonusers). No significant difference in the incidence of VTE was observed between the current users and non-users of strontium ranelate (6.8 versus 7.0 per 1,000 PY; HR, 0.90 [95\% CI, 0.46-1.75]); similar results were obtained with alendronate sodium (6.2 versus 7.2 per 1,000 PY; HR, 0.99 [95\% CI, 0.80-1.23]).

\section{Discussion}

To our knowledge, this is the first study to compare the incidence of VTE in osteoporotic and non-osteoporotic women. We found a significant $43 \%$ increase in the ageadjusted risk for VTE in untreated osteoporotic patients versus non-osteoporotic women. The profiles of our cohorts are consistent with the known major characteristics and risk factors for VTE $[2,29,30]$. It is well-known that the risk for VTE is increased in the elderly [23, 30], which is a population exposed to an increasing number of risk factors (e.g., fractures, hospitalisations, and heart disease). In our study, the incidence of VTE in the non-osteoporotic cohort was 2.4 per 1,000 PY for those aged 50 to 74 years, 5.2 per 1,000 PY between 75 and 80 years old, and 6.1 per 1,000 PY for those over 80 years. A similar increase was observed in untreated osteoporotic patients from 4.3 to 8.3 
per 1,000 PY in patients aged between 50 and 74 years and those over 80 years, respectively. These results are in the same range to those described elsewhere [29, 31, 32].

History of previous VTE is a major risk factor of recurrence of the condition [30]. In our study, the number of patients with a previous medical history of VTE was higher in the untreated osteoporotic patients than in the non-osteoporotic patients. This could partly explain the observations of further recurrence of VTE in untreated osteoporotic patients. However, when the results were adjusted for medical history of VTE and additional risk factors, such as age, BMI, and use of oral corticosteroids for more than 3 months, the risk of VTE was still higher in untreated osteoporotic patients. These results suggest that if these covariates participate in the risk of VTE, there is at least another risk factor most likely related to osteoporotic disease itself.

Osteoporotic patients, generally, have a poor gait, an increased tendency to fall, and have related injuries such as fractures [33]. For example, the lifetime risk of hip fracture was estimated to be $17.5 \%$ in Caucasian women based on a life expectancy of 78.9 years [34]. Thus, osteoporosis and related health issues lead to decreased mobility, which is a known risk factor for VTE. Moreover, trauma and orthopaedic surgery are among the strongest risk factors for VTE $[35,36]$. Indeed, several reports have described that surgery is associated with a 6 - to nearly 13 -fold increased in the risk of VTE $[23,26,29]$. Orthopaedic surgery of the hip and knee has been reported to lead to thrombosis in $30 \%$ to $50 \%$ of patients without thromboprophylaxis [2]. Therefore, osteoporosis and its complications, fractures in particular, appear to be associated with an increased risk for VTE.

Strontium ranelate is an anti-osteoporotic treatment for which meta-analysis of the pivotal phase III clinical studies indicated that the annual incidence of VTE was $0.9 \%$ over 5 years in the strontium ranelate group versus $0.6 \%$ in the placebo group, with a relative risk of 1.4 (95\% CI, 1.0-2.0) [11]. There is no known rationale or clear explanation for this difference in the incidence of VTE between strontium ranelate and placebo. In a study performed in elderly women, strontium ranelate did not affect global primary and secondary haemostatic parameters [37]. In the present study, there was no statistically significant difference in the incidence of VTE between osteoporotic patients treated with strontium ranelate and the untreated osteoporotic cohort. These results are in accordance with a recent study using a self-controlled case series method in the GPRD that did not show a greater association of VTE with strontium ranelate treatment [20]. In our study, we have included larger population with a longer follow-up, and thus, results are more informative and strengthened. Furthermore, the incidence of VTE with strontium ranelate is very similar to that for osteoporotic patients treated with alendronate sodium, a treatment for which a greater association with VTE has never been shown [38-40].

This study has some limitations since it is a retrospective study cohort with no randomisation process to define the populations and with incomplete or unmeasured confounding factors such as severity of osteoporosis, immobilisation, prolonged travel, and family history of VTE. To take into account differences between treated and untreated groups, multiple adjustments on risk factors of VTE have been performed. However, even if the main risk factors have been taken into account, we cannot rule out residual confounding effect. In addition, as strontium ranelate is a new anti-osteoporotic treatment the population treated with strontium ranelate is smaller, and the mean follow-up duration is shorter when compared to alendronate sodium cohort studied. For these reasons, a certain imbalance in analyses could not be excluded, and therefore, this study does not provide the same level of proof than doubleblinded placebo controlled clinical trials.

However, we should note that the population profile of this study is in conformity with what might be expected in terms of characteristics and observed increased risk for VTE with age. Furthermore, the fact that our study did not show an association between strontium ranelate treatment and increased risk for VTE, when compared with untreated patients, is reinforced by robustness analyses demonstrating no difference between current users and non-users. Finally, the rates of mortality were similar in the two treated cohorts (2.9\% in the strontium ranelate cohort and $4.0 \%$ in the alendronate sodium cohort) avoiding any doubts regarding the potential under-reporting of VTE leading to death and therefore, removing the bias of not diagnosed VTE.

In conclusion, this study shows for the first time that osteoporosis is associated with increased risk for VTE, probably related to the osteoporotic disease itself and its associated comorbidities. In addition, our study suggests that in current practice treatment with strontium ranelate does not carry an additional risk of VTE compared to that previously observed in clinical trials.

Conflicts of interest Dr. N. Deltour is an employee of I.R.I.S (Institut de Recherche International Servier). Dr. Jean-Yves Reginster has the following conflicts: Consulting fees or paid advisory boards Servier, Novartis, Negma, Lilly, Wyeth, Amgen, GlaxoSmithKline, Roche, Merckle, Nycomed, NPS, Theramex, UCB; Lecture fees when speaking at the invitation of a commercial sponsor - Merck Sharp \& Dohme, Lilly, Rottapharm, IBSA, Genevrier, Novartis, Servier, Roche, GlaxoSmithKline, Teijin, Teva, Ebewee Pharma, Zodiac, Analis, Theramex, Nycomed, Novo-Nordisk; Grant Support from Industry Bristol Myers Squibb, Merck Sharp \& Dohme, Rottapharm, Teva, Lilly, Novartis, Roche, GlaxoSmithKline, Amgen, Servier.

Open Access This article is distributed under the terms of the Creative Commons Attribution Noncommercial License which permits any noncommercial use, distribution, and reproduction in any medium, provided the original author(s) and source are credited. 


\section{References}

1. Spencer FA, Emery C, Lessard D, Anderson F, Emani S, Aragam J, Becker RC, Goldberg RJ (2006) The Worcester venous thromboembolism study: a population-based study of the clinical epidemiology of venous thromboembolism. J Gen Intern Med 21:722-727

2. Rosendaal FR, Van Hylckama Vlieg A, Doggen CJ (2007) Venous thrombosis in the elderly. J Thromb Haemost 5(Suppl 1):310-317

3. Silverstein RL, Bauer KA, Cushman M, Esmon CT, Ershler WB, Tracy RP (2007) Venous thrombosis in the elderly: more questions than answers. Blood 110:3097-3101

4. Kuehn BM (2008) New tool measures 10-year fracture risk. JAMA 299:1651-1652

5. Guessous I, Cornuz J, Ruffieux C, Burckhardt P, Krieg MA (2008) Osteoporotic fracture risk in elderly women: estimation with quantitative heel US and clinical risk factors. Radiology 248:179-184

6. Cheung AM, Detsky AS (2008) Osteoporosis and fractures: missing the bridge? JAMA 299:1468-1470

7. Kanis JA, Burlet N, Cooper C, Delmas PD, Reginster JY, Borgstrom F, Rizzoli R (2008) European guidance for the diagnosis and management of osteoporosis in postmenopausal women. Osteoporos Int 19:399-428

8. Maclaughlin EJ, Sleeper RB, McNatty D, Raehl CL (2006) Management of age-related osteoporosis and prevention of associated fractures. Ther Clin Risk Manag 2:281-295

9. Roux C (2008) Strontium ranelate: short- and long-term benefits for post-menopausal women with osteoporosis. Rheumatology (Oxford) 47(Suppl 4):iv20-iv22

10. Elliot-Gibson V, Bogoch ER, Jamal SA, Beaton DE (2004) Practice patterns in the diagnosis and treatment of osteoporosis after a fragility fracture: a systematic review. Osteoporos Int 15:767-778

11. EMEA (2008) SPC: summary product characteristics (EMEA 2008)

12. Jick H, Derby LE, Myers MW, Vasilakis C, Newton KM (1996) Risk of hospital admission for idiopathic venous thromboembolism among users of postmenopausal oestrogens. Lancet 348:981-983

13. Cummings SR, Eckert S, Krueger KA, Grady D, Powles TJ, Cauley JA, Norton L, Nickelsen T, Bjarnason NH, Morrow M, Lippman ME, Black D, Glusman JE, Costa A, Jordan VC (1999) The effect of raloxifene on risk of breast cancer in postmenopausal women: results from the MORE randomized trial. Multiple Outcomes of Raloxifene Evaluation. JAMA 281:2189-2197

14. Vickers MR, MacLennan AH, Lawton B, Ford D, Martin J, Meredith SK, DeStavola BL, Rose S, Dowell A, Wilkes HC, Darbyshire JH, Meade TW (2007) Main morbidities recorded in the women's international study of long duration oestrogen after menopause (WISDOM): a randomised controlled trial of hormone replacement therapy in postmenopausal women. BMJ 335:239

15. Barrett-Connor E, Mosca L, Collins P, Geiger MJ, Grady D, Kornitzer M, McNabb MA, Wenger NK (2006) Effects of raloxifene on cardiovascular events and breast cancer in postmenopausal women. N Engl J Med 355:125-137

16. Jick H, Jick SS, Derby LE (1991) Validation of information recorded on general practitioner based computerised data resource in the United Kingdom. BMJ 302:766-768

17. Jick SS, Kaye JA, Vasilakis-Scaramozza C, Garcia Rodriguez LA, Ruigomez A, Meier CR, Schlienger RG, Black C, Jick H (2003) Validity of the general practice research database. Pharmacotherapy 23:686-689

18. Lawrenson R, Todd JC, Leydon GM, Williams TJ, Farmer RD (2000) Validation of the diagnosis of venous thromboembolism in general practice database studies. Br J Clin Pharmacol 49:591-596

19. Ray WA (2003) Evaluating medication effects outside of clinical trials: new user designs. Am J Epidemiol 158:915-920

20. Grosso A, Douglas I, Hingorani A, MacAllister R, Smeeth L (2008) Post-marketing assessment of the safety of strontium ranelate: a novel case-only approach to the early detection of adverse drug reactions. Br J Clin Pharmacol 66:689-694

21. Farrington CP (2004) Control without separate controls: evaluation of vaccine safety using case-only methods. Vaccine 22:2064-2070

22. Decensi A, Maisonneuve P, Rotmensz N, Bettega D, Costa A, Sacchini V, Salvioni A, Travaglini R, Oliviero P, D'Aiuto G, Gulisano M, Gucciardo G, del Turco MR, Pizzichetta MA, Conforti S, Bonanni B, Boyle P, Veronesi U (2005) Effect of tamoxifen on venous thromboembolic events in a breast cancer prevention trial. Circulation 111:650-656

23. Heit JA, Silverstein MD, Mohr DN, Petterson TM, Lohse CM, O'Fallon WM, Melton LJ III (2001) The epidemiology of venous thromboembolism in the community. Thromb Haemost 86:452-463

24. Scottish Intercollegiate Guidelines Network (2002) Prophylaxis of Venous Thromboembolism: a national clinical guideline. SIGN, Edinburgh

25. National Institute for Clinical Excellence (2007) Venous thromboembolism: reducing the risk of venous thromboembolism (deep vein thrombosis and pulmonary embolism) in in-patients undergoing surgery. NICE Clinical guideline

26. Huerta C, Johansson S, Wallander MA, Garcia Rodriguez LA (2007) Risk factors and short-term mortality of venous thromboembolism diagnosed in the primary care setting in the United Kingdom. Arch Intern Med 167:935-943

27. Fimognari FL, Repetto L, Moro L, Gianni W, Incalzi RA (2005) Age, cancer, and the risk of venous thromboembolism. Crit Rev Oncol Hematol 55:207-212

28. Kyrle PA, Eichinger S (2005) Venous thromboembolism in men and women. J Men's Health \& Gender 2:302-308

29. Naess IA, Christiansen SC, Romundstad P, Cannegieter SC, Rosendaal FR, Hammerstrom J (2007) Incidence and mortality of venous thrombosis: a population-based study. J Thromb Haemost 5:692-699

30. White RH (2003) The epidemiology of venous thromboembolism. Circulation 107:I4-I8

31. Silverstein MD, Heit JA, Mohr DN, Petterson TM, O'Fallon WM, Melton LJ III (1998) Trends in the incidence of deep vein thrombosis and pulmonary embolism: a 25 -year population-based study. Arch Intern Med 158:585-593

32. Oger E (2000) Incidence of venous thromboembolism: a community-based study in Western France. EPI-GETBP Study Group. Groupe d'Etude de la Thrombose de Bretagne Occidentale. Thromb Haemost 83:657-660

33. McClung MR, Geusens P, Miller PD, Zippel H, Bensen WG, Roux C, Adami S, Fogelman I, Diamond T, Eastell R, Meunier PJ, Reginster JY (2001) Effect of risedronate on the risk of hip fracture in elderly women. Hip Intervention Program Study Group. N Engl J Med 344:333-340

34. Melton LJ III (2000) Who has osteoporosis? A conflict between clinical and public health perspectives. J Bone Miner Res 15:2309-2314

35. Rosendaal FR (1999) Risk factors for venous thrombotic disease. Thromb Haemost 82:610-619

36. Kwong LM (2004) Hip fracture and venous thromboembolism in the elderly. J Surg Orthop Adv 13:139-148

37. Halil M, Cankurtaran M, Yavuz BB, Ulger Z, Piskinpasa S, Gedik A, Haznedaroglu IC, Kirazli S, Ariogul S (2007) Short-term hemostatic safety of strontium ranelate treatment in elderly women with osteoporosis. Ann Pharmacother 41:41-45

38. Strampel W, Emkey R, Civitelli R (2007) Safety considerations with bisphosphonates for the treatment of osteoporosis. Drug Saf 30:755-763

39. Rosen CJ (2005) Clinical practice. Postmenopausal osteoporosis. N Engl J Med 353:595-603

40. Diel IJ, Bergner R, Grotz KA (2007) Adverse effects of bisphosphonates: current issues. J Support Oncol 5:475-482 